\title{
Características da fermentação da silagem obtida em diferentes tipos de silos sob efeito do tamanho de partícula e da altura de colheita das plantas de milho
}

\author{
Characteristics fermentative obtained of the different silos type silage a effect of particle size and \\ cutting height of corn plant
}

\author{
Mikael Neumann ${ }^{\mathrm{I}}$ Paulo Roberto Frenzel Mühlbach ${ }^{\mathrm{II}}$ José Laerte Nörnberg $^{\text {III }}$ Paulo Roberto Ost ${ }^{\mathrm{IV}}$ \\ João Restle ${ }^{\mathrm{V}}$ Itacir Elói Sandini $^{\mathrm{IV}}$ Marco Auréilo Romano ${ }^{\mathrm{IV}}$
}

\section{RESUMO}

O experimento foi conduzido no Núcleo de Produção Animal da Universidade Estadual do Centro Oeste do Paraná (UNICENTRO) e teve como objetivo avaliar a qualidade das silagens obtidas e o nível de perdas de matéria seca (MS), de proteína bruta (PB) e de fibra em detergente neutro (FDN) ocorridas durante o processo fermentativo em dois tipos de silo (experimental de PVC e semitrincheira), bem como avaliar a eficiência de compactação (densidade) do material ensilado. A forrageira utilizada foi a planta inteira de milho, que foi triturada em dois tamanhos de partícula (pequena: entre 0,2 e 0,6cm, ou grande: entre 1,0 e 2,0 cm) e cortada a duas alturas da superfície (baixo: $15 \mathrm{~cm}$, ou alto: $39 \mathrm{~cm}$ ), utilizando-se de três repetições (tipo de silo) para cada silagem, compondo-se oito tratamentos num esquema fatorial $2 \times 2 \times 2$. Os teores de MS e PB das silagens não foram afetados $(P>0,05)$ pelo tamanho de partícula, pela altura de colheita $e$ pelo tipo de silo utilizado. Por outro lado, as silagens produzidas nos dois tipos de silo diferiram quanto aos teores de matéria orgânica, FDN e $N$ amoniacal em relação ao teor de $N$ total, como também diferiram quanto ao grau de acidez $(p H)$, densidade e perdas de PB e FDN. A densidade também foi afetada $(P<0,05)$ pelo tamanho de partícula da silagem.

Palavras-chave: eficiência de compactação, perdas de silagem, silos de armazenamento.

\section{ABSTRACT}

The experiment was conducted at the Núcleo de Produção Animal of the Universidade Estadual do Centro Oeste do Paraná (UNICENTRO). It was aimed at evaluating the silage obtained quality and dry matter (DM), crude protein (CP) and neutral detergent fiber (NDF) losses occurred during fermentative process on two silos type ( $P V C$ type and commercial type) as well as evaluate the compact efficiency of silage. The forage used was corn plant harvested of the different particle sizes (small: between 0.2 and $0.6 \mathrm{~cm}$ or large: between 1.0 and $2.0 \mathrm{~cm}$ ) and cutting heights (low cut: $15 \mathrm{~cm}$ or high cut: $39 \mathrm{~cm}$ ), using three replication (silos type) for every silage, contained eight treatments in factorial scheme $2 \times 2 \times 2$. The values of dry matter and crude protein contend of the silages no presented effect associated or isolated $(P>.05)$ front of particle size (small and large), height cutting (low and high) and conservation silo type (PVC type and commercial type). On the other hand, the production silages in silos PVC type and commercial type showed differences for parameters: organic matter, neutral detergent fiber and $N$ amoniacal contends, as well amount of $\mathrm{pH}$, compact efficiency, and crude protein and neutral detergent nitrogen losses. The compact efficiency also was affected $(P<.05)$ buy the silage particle size.

Key words: efficiency compact, silage losses, store silos.

\section{INTRODUÇÃO}

A eficiência dos sistemas de conservação de forragens não deve ser avaliada somente pelo valor nutritivo do produto final, mas também pelas perdas que ocorrem da colheita das plantas até a alimentação dos animais. As perdas dos nutrientes durante a

INúcleo de Produção Animal, Curso de Medicina Veterinária, Universidade Estadual do Centro-Oeste (UNICENTRO). Rua Simeão Camargo Varela de Sá, 03, Centro de Ciências Agrárias e Ambientais, 85040-080, Guarapuava, PR, Brasil. E mail: mikaelneumann@hotmail.com. Autor para correspondência.

IICurso de Pós-graduação em Zootecnia, Universidade Federal do Rio Grande do Sul (UFRGS). Porto Alegre, RS, Brasil. E mail: muhlbach@orion.ufrgs.br.

IIIDepartamento de Tecnologia e Ciências dos Alimentos, Universidade Federal de Santa Maria (UFSM), Santa Maria, RS, Brasil.

Iv Núcleo de Produção Animal, Curso de Medicina Veterinária, UNICENTRO, Guarapuava, PR, Brasil.

${ }^{\text {v} C u r s o ~ d e ~ P o ́ s-g r a d u a c ̧ a ̃ o ~ e m ~ Z o o t e c n i a, ~ U n i v e r s i d a d e ~ F e d e r a l ~ d e ~ G o i a ́ s ~(U F G), ~ G o i a ̂ n i a, ~ G O, ~ B r a s i l . ~}$ 
ensilagem são de difícil mensuração, necessitando de metodologias específicas e precisas. A quantificação exata das perdas depende da coleta de amostras que representem a condição do armazenamento (BOLSEN, 1996).

No Brasil, poucos trabalhos de pesquisa foram realizados visando à quantificação das perdas absolutas que ocorrem na ensilagem e, na maior parte, esses não representam a real situação do produtor, pois a maioria das pesquisas foi conduzida utilizando-se de silos laboratoriais (comparando efeitos de tratamentos), em condições que não refletem a realidade do processo. Em especial, não se dispõe de dados sistematicamente produzidos sobre as perdas que ocorrem durante a "ensilagem” e "desensilagem” do material, as quais, segundo McDONALD et al. (1991) e BOLSEN et al. (1996), podem acrescentar até $20 \%$ de perdas no processo.

Em revisão de literatura, NEUMANN (2005) constatou que grande parte dos trabalhos de pesquisa, que avaliaram a qualidade e o valor nutritivo da silagem (BORGES et al., 1997; RODRIGUEZ et al., 1998; GONÇALVES et al., 1999; PESCE et al., 2000), foram realizados em silos experimentais de PVC (tipo laboratorial), que podem, em muitos casos, não refletir a realidade do processo de armazenamento da silagem que ocorre nas propriedades, já que estas utilizam outros tipos de silo (tipo trincheira e de superfície ou tipo torta) e operam com quantidades muito maiores.

Na cultura do milho, vários aspectos causam variações na qualidade da silagem, como o híbrido utilizado, estádio de maturação na colheita, além de aspectos relativos ao solo e ao clima. Na confecção das silagens, segundo NUSSIO (1995), aspectos ligados ao tamanho das partículas e à altura de colheita das plantas afetam o grau de compactação (quanto menor a partícula e maior a altura de colheita, tanto melhor a compactação) e, por conseqüência, a condição alcançada de anaerobiose, que é decisiva no processo de fermentação e conservação. Contudo, na prática, busca-se também maior rapidez no processo, o que é facilitado quando a ensiladeira é regulada para um maior tamanho de picagem do material e maior altura de corte. Assim, é de grande interesse prático uma avaliação metódica e científica das perdas que podem ocorrer em ambos os casos no processo de ensilagem.

Este trabalho teve como objetivo avaliar a qualidade das silagens obtidas e o nível de perdas de matéria seca, de proteína bruta e de fibra em detergente neutro ocorridas durante o processo fermentativo em dois tipos de silo (experimental de PVC e semitrincheira), bem como avaliar a eficiência de compactação a partir da colheita de plantas de milho em dois tamanhos de partícula e duas alturas de corte.

\section{MATERIAL E MÉTODOS}

O experimento foi conduzido no Núcleo de Produção Animal da Universidade Estadual do Centro Oeste do Paraná (UNICENTRO), utilizando-se de forragem proveniente da planta inteira de milho com grau de maturação adequado para ensilagem. Foram avaliados oito tratamentos obtidos segundo um arranjo fatorial 2 × 2 × 2, sendo dois tamanhos de partícula da forragem a ser ensilada (pequena, entre 0,2 e $0,6 \mathrm{~cm}$, ou grande, entre 1,0 e $2,0 \mathrm{~cm})$, duas alturas de corte das plantas (baixo: $15 \mathrm{~cm}$, ou alto: $39 \mathrm{~cm}$ ) e dois tipos de silo de armazenamento (de campo e experimental). Cada uma das forragens foi ensilada, com três repetições. O delineamento experimental utilizado foi o inteiramente casualizado, e os dados coletados para cada variável foram submetidos à análise de variância, por intermédio do programa estatístico SAS (1993), e as diferenças entre as médias foram analisadas pelo teste de Tukey ao nível de significância de 5\%.

O silo de campo era do tipo semitrincheira, com dimensões de $10 \mathrm{~m}$ de comprimento, $1,75 \mathrm{~m}$ de largura e $1 \mathrm{~m}$ de altura. O silo experimental era constituído de PVC, com dimensões de 0,5m de comprimento e $0,1 \mathrm{~m}$ de diâmetro, equipado com válvula de "Bunsen”. Foram colhidas amostras do material original e das silagens para avaliação de alguns parâmetros qualitativos e das perdas ocorridas durante o processo de fermentação. As amostras das silagens foram colhidas diretamente dos silos experimentais e de três bolsas de náilon que foram locadas dentro de cada silo de campo no momento da confecção das silagens.

Durante a ensilagem, na confecção de cada silo de campo, foram locadas três bolsas no perfil do silo contendo material original com peso conhecido. As bolsas foram confeccionadas com náilon maleável 100\% poliamina, com poros de 85 micrômetros, dimensões de 12 x 50cm de diâmetro e comprimento, respectivamente, com capacidade média de $2.000 \mathrm{~g}$, com nível de compactação prévio aproximado de $350 \mathrm{~kg} \mathrm{~m}^{-3}$ de matéria verde (material original). As três bolsas foram dispostas em três pontos do silo (parte inicial, parte intermediária e parte final).

Cada bolsa foi identificada, pesada individualmente vazia, e novamente pesada após seu enchimento com material original em uma balança digital com precisão de um grama. Para vedar as bolsas foram utilizados lacres do tipo braçadeira flexível de PVC. A compactação final da massa contida nas bolsas foi 
efetuada pelo trator no silo, buscando a mesma compactação entre material original da bolsa e do silo. No momento de inserção das bolsas em cada um dos silos tipo semitrincheira, paralelamente, amostras semelhantes (homogêneas e representativas) dos materiais originais foram coletadas para congelamento, pré-secagem e ensilagem nos 12 silos experimentais do tipo PVC, com o propósito de comparar a fermentação desses silos aos silos semitrincheira.

A abertura dos 12 silos do tipo semitrincheira, ocorreu 150 dias após a ensilagem. O resgate das bolsas ocorreu com o aparecimento dos mesmos no painel dos silos no decorrer do período de desensilagem para alimentação de animais confinados, nos três pontos pré-determinados dos silos. Já a abertura dos 12 silos do tipo laboratorial de PVC, ocorreu 160 dias após a ensilagem, paralelamente ao resgate das bolsas da parte inicial dos silos do tipo semitrincheira.

Nas amostras de silagens contidas em cada bolsa ou silo de PVC, uma parte na forma "in natura" foi utilizada para determinação de $\mathrm{pH}$ e nitrogênio amoniacal, enquanto a outra parte foi pesada e présecada em estufa de ar forçado a $55^{\circ} \mathrm{C}$ por 72 horas, sendo sequencialmente retirada da estufa e pesada novamente para determinação do teor de matéria parcialmente seca e moída em moinho tipo "Wiley", com peneira de malha de $1 \mathrm{~mm}$.

Nas amostras pré-secas, determinou-se a matéria seca total (MS) em estufa a $105^{\circ} \mathrm{C}$, proteína bruta (PB) pelo método micro Kjeldahl, matéria mineral (MM) por incineração a $550^{\circ} \mathrm{C}$ (4 horas) e matéria orgânica $(\mathrm{MO})$ por diferença $(\% \mathrm{MO}=100$ - MM), conforme AOAC (1995). Foram determinados os teores de fibra em detergente neutro (FDN), conforme VAN SOEST et al. (1991), utilizando-se a amilase termoestável (Termamyl 120L, Novozymes Latin América Ltda.).

As amostras "in natura” do material original e das silagens, foram prensadas, utilizando-se de uma prensa hidráulica “Carver”, modelo C, para extração do suco, que foi imediatamente utilizado para as determinações do pH através de potenciômetro digital (Digimed) e do nitrogênio amoniacal como porcentagem do nitrogênio total (N-NH3/NT), através de destilação com óxido de magnésio e cloreto de cálcio, conforme técnica descrita pela AOAC (1995).

A eficiência de compactação ( $\mathrm{kg}$ de $\mathrm{MS} \mathrm{m}^{-3}$ ) foi avaliada através da desensilagem utilizando-se um anel metálico de $10 \mathrm{~cm}$ de diâmetro e $15 \mathrm{~cm}$ de comprimento introduzido sob pressão na massa estruturada da face dos silos semitrincheira para a retirada de um volume definido de silagem compactada e subseqüente pesagem e amostragem.

As perdas de MS, PB e FDN foram expressas por diferença de gradientes entre material original e material desensilado, associado ao peso das bolsas ou dos silos de PVC na ensilagem e na desensilagem. Também foram realizadas comparações entre os teores de MS, PB, MO, FDN, pH e N-NH3/NT do material original, das silagens resultantes dos silos de PVC e das silagens das bolsas inseridas nos silos semitrincheira.

\section{RESULTADOS E DISCUSSÃO}

Na tabela 1 são apresentados os valores médios de MS, PB, MO, FDN, pH e N-NH3/NT da planta de milho (material original) e de silagens obtidas em silos laboratoriais ou de campo, em função do tamanho de partícula e altura de colheita das plantas. Não houve interação $(\mathrm{P}>0,05)$ entre altura de corte, tamanho de partícula e tipo de material para MS, PB, MO, FDN, pH e N-NH3/NT.

Para os teores médios de MS e PB, respectivamente, maiores valores $(\mathrm{P}<0,05)$ foram observados no material original (30,8 e 6,7\%) em relação à silagem resultante de silos de campo tipo semitrincheira (28,5 e 5,7\%); ambos não diferiram ( $\mathrm{P}>0,05)$ da silagem resultante de silos de PVC (29,6 e 6,5\%), que apresentou valores intermediários. Já para o teor de $\mathrm{MO}$, valores similares $(\mathrm{P}>0,05)$ foram verificados no material original $(96,2 \%)$ e na silagem resultante de silos de PVC (96,2\%); ambos, porém, foram superiores $(\mathrm{P}<0,05)$ aos obtidos na silagem resultante de silos de campo tipo semitrincheira (96,0\%).

Segundo RODRIGUES et al. (2002) a literatura apresenta grande diversidade de silos utilizados em experimentos para avaliação do valor nutritivo da silagem. Embora aceite-se que tais unidades de experimentação reproduzam as condições anaeróbias básicas, para avaliar a silagem, há indícios de que, dependendo das condições de armazenamento, os resultados obtidos possam não representar exatamente aqueles observados a campo. GONÇALVES et al. (1999) e PESCE et al. (2000), avaliando híbridos de sorgo ensilados em silos de PVC, observaram inexistência aparente de fermentações secundárias e pequenas variações ocorridas no processo de fermentação dos híbridos estudados. Tais fatos foram atribuídos ao tipo de silo utilizado ou ao tipo de vedação empregada.

Os teores de FDN do material original (Tabela 1), quando comparados aos das silagens dos silos de PVC ou de campo semitrincheira, diferiram 
Tabela 1 - Teores médios de matéria seca (MS), proteína bruta (PB), matéria orgânica (MO), fibra em detergente neutro (FDN), pH e N$\mathrm{NH}_{3} / \mathrm{NT}$ da planta de milho (material original) e de silagens obtidas em silos laboratoriais ou de campo, em função do tamanho de partícula e da altura de colheita das plantas.

\begin{tabular}{|c|c|c|c|c|c|}
\hline \multicolumn{2}{|c|}{ Ensilagem } & \multicolumn{4}{|c|}{ Tipo de material } \\
\hline \multirow[t]{2}{*}{$\begin{array}{l}\text { Tamanho de } \\
\text { partícula }\end{array}$} & Altura de colheita & Material original & $\begin{array}{l}\text { Silo de PVC tipo } \\
\text { laboratorial }\end{array}$ & $\begin{array}{l}\text { Silo de campo tipo } \\
\text { trincheira }\end{array}$ & Média \\
\hline & & \multicolumn{4}{|c|}{ MS, \% } \\
\hline Pequena & Baixa & 31,3 & 29,0 & 28,9 & 29,7 a \\
\hline Grande & Baixa & 29,9 & 28,8 & 29,1 & 29,3 a \\
\hline Pequena & Alta & 31,5 & 31,6 & 29,0 & 30,7 a \\
\hline \multirow[t]{3}{*}{ Grande } & Alta & 30,4 & 29,4 & 27,1 & 28,9 a \\
\hline & & $30,8 \mathrm{~A}$ & $29,7 \mathrm{AB}$ & 28,5 B & \\
\hline & & \multicolumn{4}{|c|}{$\mathrm{PB}, \% \mathrm{MS}$} \\
\hline Pequena & Baixa & 6,3 & 6,6 & 5,6 & 6,1 a \\
\hline Grande & Baixa & 7,0 & 6,3 & 6,0 & 6,5 a \\
\hline Pequena & Alta & 6,9 & 6,6 & 5,8 & 6,5 a \\
\hline \multirow[t]{3}{*}{ Grande } & Alta & 6,6 & 6,4 & 5,4 & $6,1 \mathrm{a}$ \\
\hline & & $6,7 \mathrm{~A}$ & $6,5 \mathrm{AB}$ & $5,7 \mathrm{~B}$ & \\
\hline & & \multicolumn{4}{|c|}{ MO, \% MS } \\
\hline Pequena & Baixa & 96,3 & 95,8 & 95,8 & 95,9 a \\
\hline Grande & Baixa & 96,0 & 96,3 & 95,9 & $96,1 \mathrm{a}$ \\
\hline Pequena & Alta & 96,1 & 96,5 & 96,0 & $96,2 \mathrm{a}$ \\
\hline \multirow[t]{3}{*}{ Grande } & Alta & 96,3 & 96,0 & 96,1 & $96,2 \mathrm{a}$ \\
\hline & & $96,2 \mathrm{~A}$ & $96,1 \mathrm{~A}$ & $96,0 \mathrm{~B}$ & \\
\hline & & \multicolumn{4}{|c|}{ FDN, \% MS } \\
\hline Pequena & Baixa & 58,4 & 52,5 & 59,0 & 56,6 a \\
\hline Grande & Baixa & 55,4 & 55,3 & 58,3 & 56,4 a \\
\hline Pequena & Alta & 56,4 & 50,6 & 56,1 & $54,4 \mathrm{a}$ \\
\hline \multirow[t]{3}{*}{ Grande } & Alta & 56,6 & 53,8 & 59,1 & $56,5 \mathrm{a}$ \\
\hline & & 56,7 B & $53,1 \mathrm{C}$ & $58,1 \mathrm{~A}$ & \\
\hline & & \multicolumn{4}{|c|}{$\mathrm{pH}$, índice } \\
\hline Pequena & Baixa & 4,6 & 3,7 & 3,2 & 3,9 a \\
\hline Grande & Baixa & 5,4 & 3,8 & 3,6 & $4,3 \mathrm{a}$ \\
\hline Pequena & Alta & 5,2 & 3,8 & 3,5 & $4,2 \mathrm{a}$ \\
\hline \multirow[t]{3}{*}{ Grande } & Alta & 5,2 & 3,8 & 3,6 & $4,2 \mathrm{a}$ \\
\hline & & $5,1 \mathrm{~A}$ & $3,8 \mathrm{~B}$ & $3,5 \mathrm{C}$ & \\
\hline & & \multicolumn{4}{|c|}{ N-NH3/NT, \% } \\
\hline Pequena & Baixa & 1,1 & 3,4 & 2,5 & $2,3 \mathrm{a}$ \\
\hline Grande & Baixa & 1,2 & 4,1 & 2,7 & $2,7 \mathrm{a}$ \\
\hline Pequena & Alta & 1,3 & 3,4 & 2,9 & 2,6 a \\
\hline \multirow[t]{2}{*}{ Grande } & Alta & 1,1 & 3,8 & 2,5 & $2,4 \mathrm{a}$ \\
\hline & & $1,2 \mathrm{C}$ & $3,7 \mathrm{~A}$ & $2,6 \mathrm{~B}$ & \\
\hline
\end{tabular}

Médias, na linha, seguidas por letras maiúsculas diferentes diferem $(\mathrm{P}<0,05)$ pelo Teste “Tukey”.

Médias, na coluna, seguidas por letras minúsculas diferentes diferem $(\mathrm{P}<0,05)$ pelo Teste “Tukey”.

$(\mathrm{P}<0,05)$ entre si. O teor de FDN $(56,7 \%)$ no material original, respectivamente, mostrou-se superior (53,1\%) e inferior (58,1\%) com a ensilagem em silos de PVC ou campo semitrincheira. Este processo pode ser explicado, dentre outros fatores, pela respiração das partículas no momento de ensilagem, pela ocorrência de hidrólise de algum componente da FDN, em especial a hemicelulose (NEUMANN et al., 2002), ou pela

Ciência Rural, v.37, n.3, mai-jun, 2007. 
formação de efluentes (VAN SOEST, 1994) durante a fermentação, onde os compostos solúveis são aumentados ou reduzidos proporcionalmente à fração fibrosa da silagem pela formação de ácidos de fermentação.

No presente trabalho, os teores médios de $\mathrm{N}-\mathrm{NH}_{3}$ das silagens, independentemente dos tratamentos, foram abaixo de $10 \%$ do $\mathrm{N}$ total, indicando, segundo OSHIMA \& McDONALD (1978) e BORGES et al. (1997), que houve fermentação láctica adequada. Segundo VAN SOEST (1994), em situações de fermentações secundárias na silagem, o N-solúvel e o $\mathrm{N}$-amoniacal formam-se da ação de microorganismos específicos, onde as concentrações desses metabólitos são conseqüências da extensão da atividade de colônias destes microorganismos em microambientes favoráveis a seu crescimento no interior do silo. $\mathrm{O} \mathrm{pH}$ do material original $(5,1)$ foi superior $(\mathrm{P}<0,05)$ às silagens dos silos de PVC $(3,8)$ ou de campo $(3,5)$, e estas também diferiram $(\mathrm{P}<0,05)$ entre si. Já para os teores de $\mathrm{N}-\mathrm{NH}_{3} / \mathrm{NT}$, maior valor médio foi observado na silagem em silos de PVC (3,7\%) em relação ao material original $(1,2 \%)$ e às silagens de silos de campo (2,6\%).

$\mathrm{O} \mathrm{N}$-amoniacal indica a quantidade de proteína degradada durante a fase de fermentação, demonstrando as perdas de proteína verdadeira que ocorrem ao longo da fermentação, sendo, segundo PIGURINA (1991), um dos parâmetros determinantes da qualidade da fermentação. Para McDONALD et al. (1991), silagens malpreservadas apresentam níveis de amônia superiores a 20\%, sendo esta amônia derivada do catabolismo de aminoácidos, entre outros produtos de degradação como aminas, cetoácidos e ácidos graxos, por meio de três processos bioquímicos: deaminação, descarboxilação e reações de oxidação e redução.

Os teores de $\mathrm{N}-\mathrm{NH}_{3} / \mathrm{NT}$ das silagens avaliadas não apresentaram relação com as demais variáveis, em função dos baixos níveis ocorridos (valores abaixo de 5\%). GONÇALVES et al. (1999) observaram menores concentrações de $\mathrm{N}-\mathrm{NH}_{3} / \mathrm{NT}$ em silagens com maiores conteúdos de MS. Dados de literatura indicam, de maneira geral, que a diferença encontrada entre os diferentes tratamentos avaliados é resultado da proteólise que pode estar associada a diversos fatores, não somente ao teor de MS, mas às quantidades de carboidratos fermentáveis (MEESKE et al., 1993), à concentração protéica (MOISIO e HEIKONEN, 1994), ao pH, ao tempo de ensilagem e à temperatura de fermentação da silagem (RODRIGUEZ et al., 1998).

NEUMANN et al. (2005) verificaram que alguns parâmetros, como teor de MS e de PB da silagem, não demonstraram efeitos associativos ou isolados $(\mathrm{P}>0,05)$ frente aos fatores tamanho de partícula (pequena e grande) e tipo de silo de conservação (tipo experimental - PVC e tipo torta). Já as variáveis nitrogênio insolúvel na FDN, nitrogênio insolúvel na FDA, FDA, DIVMO e eficiência de compactação na base seca e na base verde tenderam a apresentar qualidade diferenciada $(\mathrm{P}<0,05)$, sob efeitos individuais de tamanho de partícula ou de tipo de silo de conservação. No entanto, parâmetros como $\mathrm{N}_{-} \mathrm{NH}_{3} / \mathrm{NT}$, $\mathrm{pH}$, teores de $\mathrm{MO}$ e FDN mostraram-se diretamente dependentes do efeito associativo entre tamanho de partícula e tipo de silo, evidenciando de forma direta a importância da realização de trabalhos de pesquisa que envolvam a análise de silagens sob condições mais próximas a realidade dos produtores, no sentido de gerar informações concretas sobre a qualidade e/ou valor nutricional da silagem.

Na tabela 2, são apresentados os valores médios da eficiência de compactação na base verde (ECMV) e seca (ECMS) e as perdas de matéria seca (PeMS), de proteína bruta (PePB) e de fibra em detergente neutro (PeFDN) de silagens obtidas em silos laboratoriais ou de campo, em função do tamanho de partícula e da altura de colheita das plantas. Não houve interação $(\mathrm{P}>0,05)$ duplas ou tripas entre altura de corte, tamanho de partícula e tipo de silo para ECMV, ECMS, PeMS, PePB, e PeFDN.

Silagens produzidas em silos de PVC tiveram maiores $(\mathrm{P}<0,05)$ ECMV $\left(531,2\right.$ contra 505,5 $\left.\mathrm{kg} \mathrm{m}^{-3}\right) \mathrm{e}$ ECMS (169,7 contra 133,6 $\mathrm{kg} \mathrm{m}^{-3}$ ) em relação às silagens produzidas em silos de campo, independentemente do tamanho de partícula e da altura de colheita das plantas, mostrando que a dinâmica de fermentação pode ser alterada modificando a qualidade final das silagens.

LOURES et al. (2003), avaliando perdas em silagens de capim-elefante sob níveis de compactação (de 300 a $800 \mathrm{~kg} \mathrm{~m}^{-3}$ de MV), verificaram efeito quadrático, em silos de PVC, com valores menores de FDN e FDA em densidades de 518,3 e 585,5kg mº, justificando os resultados dos maiores teores de FDA em densidades de $300 \mathrm{~kg} \mathrm{~m}^{-3}$ de $\mathrm{MV}$ como sendo resultado da ocorrência de reações de "Maillard", as quais produziram componentes insolúveis em detergente ácido, determinados pelas reações dos açúcares e glicídios aos aminoácidos presentes na massa ensilada, vindo a determinar aumentos também nos teores de FDN e redução dos coeficientes de digestibilidade.

LOURES et al. (2003) também sugerem que, sob densidades de $800 \mathrm{~kg} \mathrm{~m}^{-3}$, o aumento nos teores de FDN e FDA estariam relacionados a um maior consumo dos constituintes passíveis de serem solubilizados na 
Tabela 2 - Eficiência de compactação na base verde (ECMV) e seca (ECMS) e perdas de matéria seca (PeMS), de proteína bruta (PePB) e de fibra em detergente neutro (PeFDN) de silagens obtidas em silos laboratoriais ou de campo, em função do tamanho de partícula e da altura de colheita das plantas.

\begin{tabular}{|c|c|c|c|c|}
\hline \multicolumn{2}{|c|}{ Ensilagem } & \multicolumn{3}{|c|}{ Tipo de material } \\
\hline Tamanho de partícula & \multirow[t]{2}{*}{ Altura de colheita } & Silo de PVC Tipo laboratorial & Silo de campo tipo trincheira & Média \\
\hline & & \multicolumn{3}{|c|}{ ECMV, $\mathrm{kg} / \mathrm{m}^{3}$} \\
\hline Pequena & Baixa & 532,1 & 531,7 & $531,9 a$ \\
\hline Grande & Baixa & 530,5 & 491,6 & $511,1 \mathrm{~b}$ \\
\hline Pequena & Alta & 547,6 & 552,8 & $550,2 a$ \\
\hline \multirow{3}{*}{ Grande } & Alta & 514,7 & 445,8 & $480,3 \mathrm{~b}$ \\
\hline & & $531,2 \mathrm{~A}$ & $505,5 \mathrm{~B}$ & \\
\hline & & \multicolumn{3}{|c|}{ ECMS, $\mathrm{kg} / \mathrm{m}^{3}$} \\
\hline Pequena & Baixa & 168,8 & 154,5 & 161,6 \\
\hline Grande & Baixa & 163,8 & 111,1 & $137,5 \mathrm{~b}$ \\
\hline Pequena & Alta & 181,8 & 151,1 & $166,5 \mathrm{a}$ \\
\hline \multirow[t]{3}{*}{ Grande } & Alta & 164,4 & 117,8 & $141,1 \mathrm{~b}$ \\
\hline & & 169,7 A & $133,6 \mathrm{~B}$ & \\
\hline & & \multicolumn{3}{|c|}{ PeMS, \% } \\
\hline Pequena & Baixa & 0,8 & 5,4 & 3,1 a \\
\hline Grande & Baixa & 3,5 & 1,6 & $2,5 \mathrm{a}$ \\
\hline Pequena & Alta & 3,1 & 2,1 & $2,6 \mathrm{a}$ \\
\hline \multirow[t]{3}{*}{ Grande } & Alta & 2,7 & 2,8 & 2,7 a \\
\hline & & $2,5 \mathrm{~A}$ & $3,0 \mathrm{~A}$ & \\
\hline & & \multicolumn{3}{|c|}{ PePB, \% MS } \\
\hline Pequena & Baixa & 0,2 & 8,4 & 4,3 a \\
\hline Grande & Baixa & 6,7 & 12,5 & 9,6 a \\
\hline Pequena & Alta & 3,8 & 16,5 & $10,2 \mathrm{a}$ \\
\hline \multirow[t]{3}{*}{ Grande } & Alta & 3,5 & 9,1 & 6,3 a \\
\hline & & $3,5 \mathrm{~B}$ & $11,6 \mathrm{~A}$ & \\
\hline & & \multicolumn{3}{|c|}{ PeFDN, \% MS } \\
\hline Pequena & Baixa & 9,6 & 7,7 & $8,6 \mathrm{a}$ \\
\hline Grande & Baixa & $-1,0$ & $-4,4$ & $-2,7 c$ \\
\hline Pequena & Alta & 9,2 & 6,1 & $7,7 \mathrm{a}$ \\
\hline Grande & Alta & 8,7 & 4,4 & $6,5 b$ \\
\hline \multicolumn{2}{|c|}{ Média } & 6,6 A & $3,5 \mathrm{~B}$ & \\
\hline
\end{tabular}

Médias, na linha, seguidas por letras maiúsculas diferentes diferem $(\mathrm{P}<0,05)$ pelo Teste “F”.

Médias, na coluna, seguidas por letras minúsculas diferentes diferem $(\mathrm{P}<0,05)$ pelo Teste "Tukey”.

matéria seca, como os carboidratos solúveis e minerais, pela ação dos microorganismos fermentadores e/ou pela ocorrência de lixiviação ao longo do processo de ensilagem, seguindo-se a fermentação.

As eficiências de compactação da MV (541,1 contra 495,6 $\left.\mathrm{kg} \mathrm{m}^{-3}\right)$ e da MS (164,1 contra 139,3kg m³ também foram maiores $(\mathrm{P}<0,05)$ em silagens de partículas pequenas em relação às silagens de partículas grandes, respectivamente. O tamanho da partícula ensilada, em nível prático, notadamente relacionou-se diretamente com a potência do trator e/ou a regulagem da ensiladeira utilizada. O menor tamanho da partícula facilitou o processo de ensilagem, uma vez que permitiu maior densidade de transporte do material colhido até o local de armazenamento, como também aumentou a eficiência do processo de compactação e permitiu melhor fermentação anaeróbia. As conseqüências observadas foram melhor preservação do valor nutritivo da massa ensilada e minimização das perdas na desensilagem.

Com relação às perdas de matéria seca, não houve diferença $(\mathrm{P}>0,05)$ entre os silos de

Ciência Rural, v.37, n.3, mai-jun, 2007. 
armazenamento, apresentando valor médio de 2,7\%. Já para as perdas de proteína bruta e de fibra em detergente neutro, menores (3,5 contra 11,6\%) e maiores (6,6 contra $3,5 \%)$ perdas $(\mathrm{P}<0,05)$, respectivamente, foram observadas nos silos de PVC em relação aos silos de campo. As perdas de matéria seca e de proteína bruta foram similares $(\mathrm{P}>0,05)$ nas silagens de milho em função do tamanho de partícula e altura de colheita das plantas. (Tabela 2). Já nas perdas de fibra em detergente neutro, maiores valores $(\mathrm{P}<0,05)$ foram obtidos nas silagens colhidas com tamanho de partícula pequena comparativamente às silagens de partícula grande em corte baixo (-2,7\%) e em corte alto (6,5\%).

SENGER et al. (2005), avaliando silagens de milho com distintos teores de umidade e níveis de compactação, concluíram que é possível manter as características qualitativas da silagem similares ao material original e que silagens com maior teor de matéria seca ( $>28 \%$ ) e bem compactadas ( $>650 \mathrm{~kg} \mathrm{~m}^{-3}$ de MV) preservam maior quantidade de açúcares que podem ser usados como fonte de energia pelos microorganismos ruminais, pois, segundo MULLIGAN et al. (2002), silagens malcompactadas (nível de compactação abaixo de $300 \mathrm{~kg} \mathrm{~m}^{-3}$ de MV) determinam maior atividade de enzimas proteolíticas que transformam o nitrogênio protéico em formas de NNP (peptídios e aminoácidos livres), onde, sequencialmente, bactérias proteolíticas, via fermentação, transformarão estes elementos em variados ácidos orgânicos, $\mathrm{CO}_{2}$, amônia e aminas, produtos estes ligados à redução do consumo das silagens pelos animais.

Comparações entre material original e silagem de diferentes híbridos de milho realizadas por ALMEIDA FILHO et al. (1999) mostraram diminuição nos teores de FDN durante o processo de ensilagem de milho, fato que pode estar associado, segundo esses autores, à hidrólise da fração hemicelulose. Enquanto isso, para os teores de FDA, esses autores observaram variação heterogênea, com decréscimos ou acréscimos de valores na comparação das diferentes cultivares. As perdas de nutrientes da silagem geralmente é resultado da presença de $\mathrm{O}^{2}$ e conseqüente ativação de processos químicos, físicos e microbiológicos que atuam em detrimento ao valor nutritivo da silagem (McDONALD et al., 1991). Como a maioria dos trabalhos de pesquisa são realizados com silos de PVC, condições de meio ambiente são facilmente controláveis mascarando os efeitos finais sobre o valor nutritivo da silagem. WATSON e NASH (1960) analisando 800 experimentos, relatam perdas de matéria seca (MS) e de nitrogênio (N) durante a ensilagem da ordem de 16,1 e 15,2\%, respectivamente. Já ZIMMER (1967) com dados de perdas de MS de 504 experimentos, envolvendo diferentes forrageiras com diferentes teores de MS na colheita, encontrou valores variando de 0,8 a 71,0\%, com média de 19,4\%.

Os resultados obtidos no presente estudo podem ser justificados, segundo REIS e JOBIM (2001) pela elevação nos valores de FDA que pode ser efeito de diluição, em que, com o decréscimo nos conteúdos dos carboidratos solúveis e de hemicelulose (FDN), e a pequena diminuição de FDA, tendo como resultado a elevação proporcional destes valores, uma vez que os dados são expressos em \% da MS. SENGER et al. (2005), sob condições de boa (700kg m³ de MV) e má ( $400 \mathrm{~kg} \mathrm{~m}^{-3}$ de MV) compactação, verificaram que em silagens de milho úmidas (20\% de MS) os teores de FDN da silagem resultante foram superiores à forragem fresca, devido possivelmente à perda de açúcares solúveis, causando aumento dos carboidratos fibrosos, enquanto em silagens de milho mais secas (26 a 28\% de MS) os teores de FDN diminuiram com o processo de ensilagem em relação à forragem fresca, devido à redução da fração de hemicelulose consumida durante a fermentação.

\section{CONCLUSÕES}

Nas condições de realização do experimento pode-se concluir que: Independente do material avaliado (material original ou silagens), não houve efeito do tamanho de partícula e da altura de corte nos valores médios de MS, PB, FDN, pH e N-NH $/$ NT. A composição de silagens, confeccionadas em silo de laboratório (PVC) e em silo de campo (semi-trincheira), pode diferir dependendo do parâmetro avaliado. Independente do tipo de silo (de laboratório e de campo), o tamanho da partícula da forragem interfere na densidade da silagem. O tipo de silo utilizado (de laboratório e de campo) pode interferir na densidade e nas perdas de PB e de FDN das silagens.

\section{REFERÊNCIAS}

ALMEIDA FILHO, S.L. et al. Características agronômicas de cultivares de milho (Zea mays L.) e qualidade dos componentes e das silagens. Revista Brasileira de Zootecnia, v.28, n.1, p.7-13, 1999.

ASSOCIATION OF OFFICIAL ANALYTICAL CHEMISTS AOAC. Official methods of analysis. 16.ed. Washington, 1995. 2000p.

BORGES, A.L.C.C. et al. Qualidade de silagens de híbridos de sorgo de porte alto, com diferentes teores de tanino e umidade no colmo. Pesquisa Brasileira de Medicina Veterinária e Zootecnia, v.49, n.4, p.441-452, 1997. 
BOLSEN, K.K. Silage technology. In: AUSTRALIAN MAIZE CONFERENCE, 2., 1996, Queensland. [Proceedings...] Queensland: Gatton College, 1996. p.1-30.

GONÇALVES, L.C. et al. Silagem de sorgo de porte baixo com diferentes teores de tanino e de umidade no colmo. III - Quebra de compostos nitrogenados. Arquivo Brasileiro de Medicina Veterinária Zootecnia, v.51, n.6, p.571-576, 1999.

LOURES, D.R.S. et al. Características do efluente e composição químico-bromatológica da silagem de capim-elefante sob diferentes níveis de compactação. Revista Brasileira de Zootecnia, v.32, n.6(S2), p.1851-1858, 2003.

McDONALD, P. et al. The biochemistry of silage. 2.ed. Marlow: Chalcombe, 1991. 339p.

MEESKE, R. et al. Ensiling forage sorghum at two stages of maturity with the addition of lactic bacterial inoculants. Animal Feed Science and Technology, v.43, p.165-175, 1993.

MOISIO, T.; HEIKONEN, M. Lactic acid fermentation in silage preserved with formic acid. Animal Feed Science and Technology, v.47, p.107-124, 1994.

MULLIGAN, F.J. et al. Intake, digestibility, milk production and kinetics of digestión and pasaje for diets based on maize or grass silage fed to late lactation dairy cows. Livestock Production Science, s.l., v.74, p.113-124, 2002

NEUMANN, M. et al. Avaliação de diferentes híbridos de sorgo (Sorghum bicolor, L. Moench) quanto aos componentes da planta e silagens produzidas. Revista Brasileira de Zootecnia, v.31(S), n.1, p.302-312, 2002.

NEUMANN, M. et al. Efeito do tamanho da partícula e do tipo de silo sobre o valor nutritivo da silagem de sorgo (Sorghum bicolor, L. Moench). Revista Brasileira de Milho e Sorgo, v.4, n.2, p.224-242, 2005.

NUSSIO, L.G. Milho e sorgo para produção de silagem. In: PEIXOTO, A.M. et al. (Ed). Volumosos para bovinos. 2.ed. Piracicaba: FEALQ, 1995. p.75-177.

OSHIMA, M.; McDONALD, P.A. A review of changes in nitrogenous compounds in herbages during ensiling. Journal of the Science of Food and Agriculture, v.29, p.497-505, 1978.
PESCE, D.M.C. et al. Porcentagem, perda e digestibilidade in vitro da matéria seca das silagens de 20 genótipos de sorgo. Arquivo Brasileiro de Medicina Veterinária Zootecnia, v.52, n.3, p.250-255, 2000.

PIGURINA, G. Factores que afectan el valor nutritivo y la calidad de fermentacion de ensilajes. In: INSTITUTO NACIONAL DE INVESTIGACION AGROPECUÁRIA. (Ed). Pasturas y produccion animal de áreas organaderia intensiva. Montevideo, 1991. p.77-92. (Serie Tecnica, 15).

REIS, R.A.; JOBIM, C.C. Perfil da fração de carboidratos da planta e adequação de aditivos no processo de ensilagem. In: WORKSHOP SOBRE MILHO PAR SILAGEM, 2., 2001, Piracicaba. Anais... Piracicaba: FEALQ, 2001. p.27-52,

RODRIGUEZ, N.M. et al. Silagem de sorgo de porte alto com diferentes teores de tanino e de umidade no colmo. III - Quebra de compostos nitrogenados. Arquivo Brasileiro de Medicina Veterinária e Zootecnia, v.50, n.2, p.161-165, 1998.

RODRIGUES, P.H.M. et al. Composição bromatológica e perfil fermentativo da silagem de capim-elefante obtida em diferentes tipos de silos experimentais e no silo tipo trincheira. Revista Brasileira de Zootecnia, v.31, n.6, p.2386-2392, 2002.

SAS INSTITUTE. SAS/STAT user's Guide: statistics. version 6.4.ed. North Caroline, 1993. v.2, 943p.

SENGER, C.C.D. et al. Composição química e digestibilidade "in vitro" de silagem de milho com distintos teores de umidade e níveis de compactação. Ciência Rural, v.35, n.6, p.13931399, 2005.

VAN SOEST, P.J. et al. Symposium: carbohydrate methodology, metabolism, and nutritional implications in dairy cattle. Methods for dietary fiber, neutral detergent fiber, and nonstarch polysaccharides in relation to animal nutrition. Journal of Dairy Science, v.74, n.10, p.3583-3597, 1991.

VAN SOEST, P.J. Nutritional ecology of the ruminant. 2.ed. Ithaca: Cornell University, 1994. 476p.

WATSON, S.J.; NASH, M.J. The conservation of grass and forage crops. Edinburgh : Oliver and Boyd, 1960. 89p.

ZIMMER, E. Factors affecting silage fermentation, in silo. Das Wirtschaftseigene Futter, v.13, p.271-286, 1967. 